\title{
Inclusion in International Schools: Theoretical Principles, Ethical Practices, and Consequentialist Theories ${ }^{*}$
}

\author{
Julie M. Lane, David R. Jones \\ Fresno Pacific University, Fresno, USA
}

\begin{abstract}
International schools have the ability to create a global acceptance through inclusive special education school settings while serving various cultures, races, and religions. But does the inclusion of children with disabilities occur in international schools? And, if so, how do administrators' perceptions predict whether or not the school culture is inclusive? This study explores the relationship of inclusive practices, Connectedness (Frick \& Frick, 2010), the Council of Exceptional Children (CEC) Ethical Principles and Practice Standards (2010), and consequentialism. Fifty-seven participants representing 35 countries self-reported current practices and self-perceptions regarding Connectedness (Frick \& Frick, 2010), the CEC Ethical Principles and Practice Standards (2010), and consequentialism.
\end{abstract}

Keywords: international schools, special education, inclusion, ethics, consequentialism, school administrator

\section{Literature Review}

International schools often serve temporarily displaced families who reside in foreign countries (e.g., families in which one or both parents have been contracted for special employment opportunities). As of May 2015, more than four million children attend English-speaking international schools with an anticipated 12,000 international schools by the year 2024 (Barnes, 2015, pp. 8-9). Due to the nature of international schools, one would anticipate that international schools are heterogeneous communities reflecting multiple cultures, races, religions, abilities, and expectations. This is not the case. Per Shaklee (2007), due to the competitive climate of international schools and the cultural influences of the host country, international schools' admission process is selective. Nonetheless, international schools are serving a diverse population which includes children with disabilities (Shaklee, 2007; Sperandio \& Klerks, 2007). Bunnell (2006) and Haldimann (1998, 2004 as cited in Shaklee, 2007) state there is a lack of research regarding children with disabilities in international schools.

More than $3.2 \%$ of the world's population is now living outside their country of origin (United Nations, 2013, p. 2). Nearly 93 million children or one in every ten children lives with some form of disability (Global

\footnotetext{
*Acknowledgements: First and foremost, the researchers would like to acknowledge Mr. Gregg Pinick, Head of School, at Concordia Shanghai, for the conversation which sparked the interest in international school research. The researchers would like to thank the Association of American Schools in South America, Council of International British Schools, and the East Asian Regional Council of Schools for their willingness to distribute the survey. Lastly, the researchers would like to acknowledge The Next Frontier Inclusion, an international school educational initiative that seeks to empower international schools in serving children with disabilities.

Julie M. Lane, Ed.D., School of Education, Fresno Pacific University.

David R. Jones, M.S., School of Education, Fresno Pacific University.
} 
Partnership for Education, 2015, para. 1; UNESCO, 2015, para. 1). The United Nations Educational, Scientific, and Cultural Organization (UNESCO) "promotes inclusive education policies, programs, and practices to ensure equal education opportunities for persons with disabilities" (UNESCO, 2015, para. 4). In 2006, the United Nations' (UN) Convention on the Rights of Persons with Disabilities formally recognized the need to respect differences and accept those with disabilities as part of human diversity (UN, 2006, Article 3). The UN (2006) convention also supports the need to (1) promote a positive perception of those with disabilities; (2) acknowledge that those with disabilities have something to contribute to the greater good; and (3) include individuals with disabilities into mainstreamed society.

The Office of Overseas Schools (A/OS) (2014/2015) report more than 500 international schools provide disabilities programs (p. 2), however, A/OS is under the auspices of the U.S. Department of State and is not comprehensive of all data regarding neither international schools nor their organizational associations. A/OS states "Inclusion is a philosophy commitment that recognizes a right to a sense of welcome and belonging in the education of all students" (Kusuma-Powell \& Powell, 2004, para. 1). Despite Shaklee's (2007) evidence that children with disabilities are served in international schools, the number of children with disabilities in international schools does not appear to be documented. With the recent establishment of Next Frontier Inclusion, an international school service organization which promotes and protects the interest of children who learn differently or at a different rate, it would appear that international schools are recognizing the need for leadership and professional development in the disability field.

\section{Inclusion}

Educators must recognize that inclusion of children with disabilities is more than the integration of a child with disabilities into the regular education classroom. It is the development of a school culture which embraces diversity (Anderson, 2006, 2011; DiPaola, Tschannen-Moran, \& Walther-Thomas, 2004; Fiedler \& Van Haren, 2009; Hansen \& Morrow, 2012; Frick, Faircloth, \& Little; 2013; Kune, 1992). For the purposes of this paper, inclusion is defined as not just the physical integration of a child with disability in the general education setting but rather it is the establishment of a school cultural which practices acceptance. Inclusive environments reflect patience, understanding, and compassion so that all children have the opportunity to learn. This requires school administrators and educators to rethink how teaching and learning are intertwined and how all children have the same opportunity to academically, socially, and behaviorally develop and interact alongside typical peers. Bartlett (2014) states, "Rising to the greater challenge of meeting more diverse needs has raised our (international schools) overall game, making us smarter thinkers, smarter problem solvers, and critically, smarter teachers" (p. 18). Inclusion requires the re-envisioning of the classroom where the value of academics, social development, friendships, behavior, and diversity are equal and understanding, patience, and compassion are seen as traits that are essential for adult life (Anderson, 2006, 2011; DiPaola et al., 2004; Fiedler \& Van Haren, 2009; Hansen \& Morrow, 2012; Frick et al., 2013). Lastly, inclusion provides a level playing field where a disability explains why learning, socializing, and behaving may be challenging, and where disabilities are not viewed as an excuse in which children do not have the opportunity to reach their full-potential.

\section{School Administrators}

School administrators are those who hold a top tier leadership role within their school, e.g., principal, head of school, executive director. Frick and Frick (2010) identified six domains of connectedness that assist school administrators in leading and creating school communities. 
(1) Justice is practiced regardless of a defining category in which one belongs, e.g., race, religion, ability, and demonstrates the capacity to do what is good and just by placing the commitment above self to do what is right.

(2) Care is the capacity to act first for the well-being of others - especially those who are different than self.

(3) Critique requires administrators to reflect, question, and act upon the injustices of others regardless of current norms while speaking up for those who are oppressed and discriminated against.

(4) (School) community is the moral agent. Administrators are to collaborate, communicate, and dialogue with the community prior to making moral decisions.

(5) Profession is the ethical practice of placing the student's best interest at the center of the conversation while recognizing that personal values and beliefs shape our professional ethic.

(6) Virtue is a presence of openness to dialogue, to be responsibly authentic, and the practice of self-honesty and relational sensitivity. (pp. 18-22)

Frick and Frick (2010) conclude that educational leaders must develop ways to connect all members of the school community by creating effective and applicable professional development opportunities, advocating and supporting needed programing, and fostering a learning environment which embraces acceptance and awareness (p. 28). School administrators can create connected school communities by supporting all members of the school community through curriculum, professional development, and instructional strategies (Frick et al., 2013; Sergiovanni, 2007; Wendel, Hoke, \& Joekel, 1996). Jabal (2013) stated that school cultures and the needs of international schools are often imported by the vast array of cultures found within faculty, staff, and families. If so, then the effectiveness of a school administrator in an international school may depend on the administrator's ability to connect with and understand the diverse cultures (Jabal, 2013).

The school culture rests in the vision and daily practices of the school administrator (Anderson, 2006, 2011; DiPaola et al., 2004; Fiedler \& Van Haren, 2009; Hansen \& Morrow, 2012; Frick et al., 2013; Frick \& Frick, 2010; Kune, 1992; Sperandio \& Klerks, 2007). To create an inclusive school environment, administrators must first create a vision that depicts the ability of every child to learn and find success regardless of their limitations (Bakken \& Smith, 2011; Conderman \& Pedersen, 2005; DiPaola, Tschannen-Moran, \& Walther-Thomas, 2004; Frick et al., 2013). The vision must encompass the needs of the child academically, socially, and behaviorally while respecting the child's cultural background (Bakken \& Smith, 2011; DiPaola et al., 2004). Children with disabilities are more likely to find success when a school culture acknowledges and reflects that all children can succeed and when the school creates pathways for success (Hansen \& Marrow, 2012; Smith \& Leonard, 2005).

\section{Council of Exceptional Children}

The CEC Ethical Principles and Practice Standards (2010) emphasize ethics similar to those of Connectedness (Frick \& Frick, 2010). Fiedler and Van Haren (2009) concluded that school administrators must not only hold "ethical codes of conduct and professional standards" (p. 162) but must also (1) be well-versed in special education and its services in order to make ethical decisions; and (2) reflect an advocacy of concern and commitment in their school communities regarding children with disabilities (p. 172). Helton and Ray (2009) noted four types of special education ethical decisions errors made by school administrators: (1) decisions resulting from administrative pressure to practice unethically; (2) placing one's own beliefs before ethical codes of practice; (3) following administrative directives regardless of practitioner ethical responsibilities; and (4) teachers not receiving support from administrators when a child's special education plan is not being implemented (p. 115). To facilitate positive experiences for children with disabilities, school administrators 
must serve, coach, facilitate, improve, respond, mediate, and nurture healthy environments (Sheldon, Angell, Stoner, \& Roseland, 2010).

\section{Consequentialism}

The consequentialist thought was defined by Jeremy Bentham (1748-1832) on the premise that "Morally appropriate behavior will not harm others, but instead increase happiness or "unity"' (Driver, 2012, p. 7). Increasing happiness or unity is not directed at the individual but rather towards the whole. Those who threaten or act in a manner which may harm others do not foster a unity. Tasioulas (2010) indicates that when one disrupts the happiness or unity of a group, then one should then be punished because they are capable of know what they did was morally inappropriate (p. 688).

Consequentialism in its purest form is a moral value that reflects a decision that results in the best overall outcome regardless of the situation (Driver, 2012; Hooker, 2010; Mill, 2003; Scheffler, 1988). Since Bentham's time, multiple philosophical variations of consequentialism have developed (Darwall, 2005; Driver, 2012; Hooker, 2010; Mill, 2003; Scanlon, 1998) though all maintain a common thread that "moral value by instrumental or extrinsic value" is assessed based upon one's actions (Darwall, 2005, p. 27). For the purposes of this study, Unitarianism consequentialism will be utilized.

Unitarianism consequentialism assess (1) the putting aside of personal preferences (Scheffler, 1988, p. 1); and (2) the benefit of one's actions by the value to the greater good (Darwall, 2005, p. 27). A school administrator who embraces consequentialist thought may mandate a consequence for a child based solely on the child's actions rather than taking into account the rationale for the action, therefore, punishing someone who may be unaware of their error or punishing disproportionately (Tasioulas, 2010). If we embrace the value that a moral rule applies to all, then do we discriminate against the child with disabilities who may not know that they have broken a moral rule? If so, do we then discriminate against the admission of children with disabilities into international schools, lower our expectations as to their ability to learn, or punish them for actions which may be manifested in their disability? Scanlon (1998) states one may even wish to consider that equal and fairness are moral requirements and not moral goals (p. 81).

The Individuals with Disabilities Education Act in the United States requires a Manifestation Determination Meeting to determine whether or not a child's adverse behavior is manifested in the disability rather than the child electing to break school rules. The meeting is designed to determine whether or not the consequences for the child's adverse actions should be determined based upon all students verses consequences that take into account the child's disabilities. Stike and Soltis (2009) state that equal value "means that they (students) are entitled to the same basic rights and that their interests, though different, are of equal value" (p. 15). School administrators may have to exercise personal discretion (William, Pazey, Shelby, \& Yates, 2013) by stepping outside the rule or norm to make a determination (Driver, 2012, p. 1). An administrator who is a consequentialist may be in conflict with special education-related legal mandates or disability cultural norms (Brown, 2011). Scanlon (1988) states that one can build equality into the consequentialist theory if each individual is given equal worth.

\section{Methods}

To determine international school administrators' dispositions towards inclusive environments, a quantitative correlational study was developed. Researchers developed an electronic survey which would be 
distributed to international school administrators. Potential participants were identified by the researchers via an internet search for international schools and international school organizations. Email addresses that reflected school administrators via organizational websites were collected. If email addresses were not available, the organization itself was contacted by the researchers via email. Three organizations agreed to distribute the survey to their school administrators on behalf of the researchers via internal distribution lists. To encourage participation, participants had the opportunity to be included in a drawing for a US $\$ 100$ Amazon $^{\odot}$ Gift Certificate. Participants who wished to be included in the drawing submitted their email via the survey. The study sought to answer:

(1) What, if any, correlation exists between the total number of students enrolled in an international school and the number of students with disabilities served?

(2) What, if any, correlation exists between tuition and the number of students with disabilities served?

(3) What, if any, correlation exists between teachers formally trained to serve children with disabilities and the number of students with disabilities served?

(4) What, if any, correlation exists between the Ethics of Connectedness (Frick \& Frick, 2010), CEC (2010), and consequentialism, and inclusive practices?

(5) What, if any, correlations exists between each of the subscales-CEC (2010), Ethics of Connectedness (Frick \& Frick, 2010), and consequentialism?

\section{Survey Development and Subscales}

\section{CEC Ethical Principles and Practice Standards}

The researchers developed 16 statements based on the CEC Ethical Principles and Practice Standards (2010). The statements represented a combination of forward and reverse-scored items. Researchers employed a process of validation of the survey that approximated criterion reliability. There were 24 special education professionals in the norming group. After norming the statements using a concurrent rater qualitative approach, the researchers entertained the notion that respondents may have responded to one or more items from the perspective that "these things 'do' or 'do not' happen" rather than "these things 'should' happen". It is the former perspective that may contribute to skewed results as the survey intended to assess individuals' espousal of ideals rather than appraisals of whether or not such ideals characterize current practice. However, researchers employed the original design of the survey in the implementation of the current study.

\section{Ethics of Connectedness}

Frick and Frick's (2010) discussion informed the development of the connectedness sub-portion of the survey. Researchers generated 35 statements which included items that were reversed scored to control for presenter bias and to gauge for consistency and authenticity in participant responses. There were 8 pre-service school administrators in the norming group. The norming of the Connectedness scale utilized test-retest. Following review of the reliability and variance of each item and subsequent omission of items that demonstrated inverse (-) patterns, 26 items remained including six care-related, four community-related, three critique-related, three justice-related, three professionalism-related, and seven virtue-related items.

\section{Consequentialism}

The researchers composed a scenario-based assessment of consequentialist versus non-consequentialist tendencies. The development of scenarios was informed by Strike and Soltis (2009). Researchers adopted and 
modified three scenarios and collected responses via three, six-point Likert scale responses ranging from "Strongly Disagree" to "Strongly Agree" for each scenario. Two items measured tendencies toward a consequentialist perspective. One item measured tendencies toward a non-consequentialist perspective. Researchers provided one open-ended item ("What concerns you most about this situation?"). The names of key characters were replaced by gender and English neutral pseudonyms (e.g., Chris or Alex).

\section{Results}

The survey was distributed once in spring 2014 by researchers or international school organizations. Since the researchers were not able to discern how many distributed via international school organizations, it is unclear as to the total number of potential participants and the number of individuals who viewed the solicited request to participant in the study. Fifty-seven respondents completed the survey between March and April 2014. Twenty respondents initiated participation but did not complete the survey. One response set indicated a clear pattern of disingenuous participation (i.e., no variance in the option selected as a response to all Likert scale items). The number of total responses is discussed below in terms of the particular sub-portion of the survey.

\section{Demographics}

The 57 participants represented 35 countries as indicated in Figure 1.

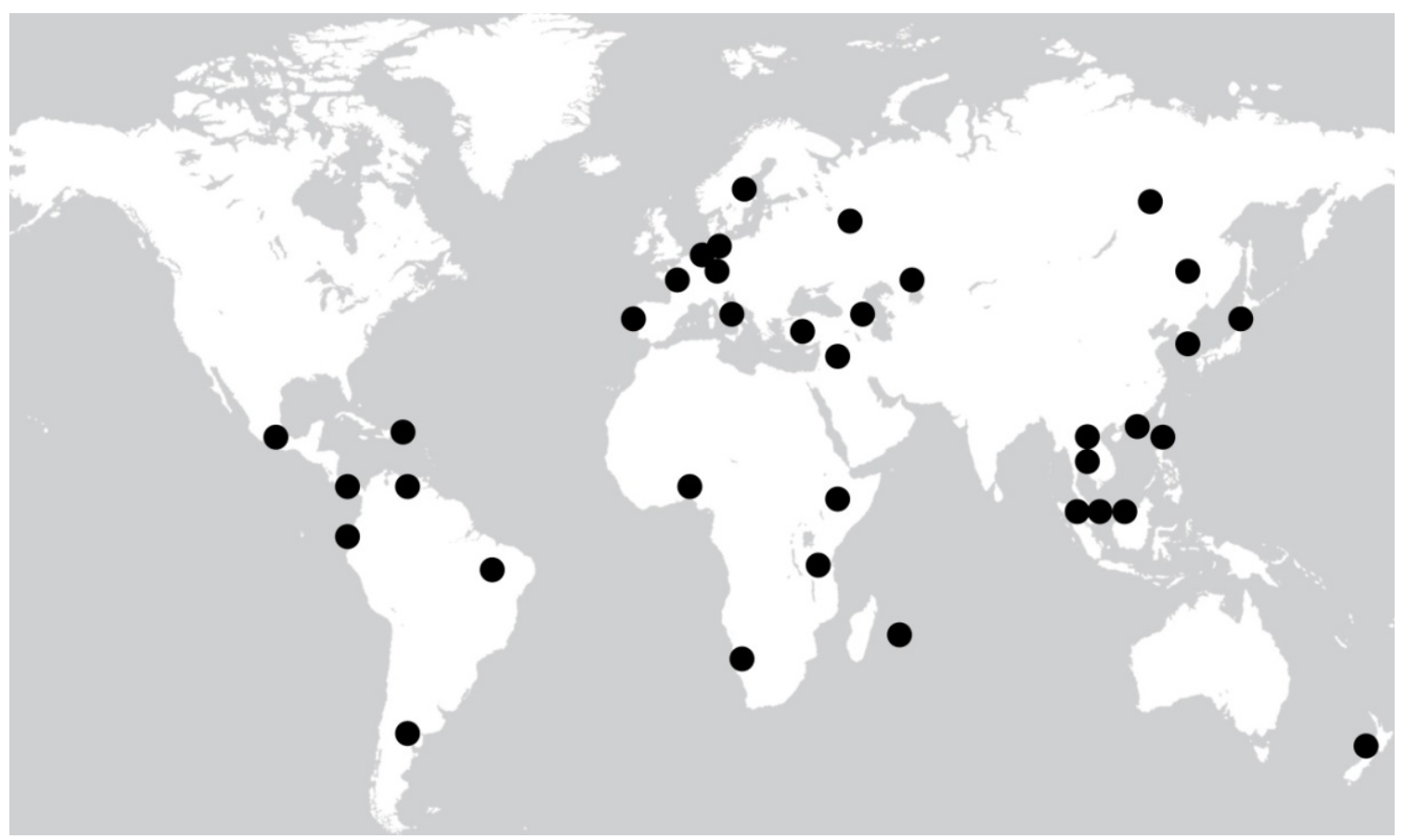

Figure 1. Geographical Dispersion of Respondents.

Fifty-six respondents indicated a nationality or nation of origin. Half $(50 \%)$ of the respondents claimed American nationality. Seven respondents (12.5\%) claimed the United Kingdom ("English") as the nation of origin. Three respondents claimed dual nationality or origin (e.g., "Filipino-American" and "Canada-UK").

Respondents included 31 males (54.39\%) and 23 females (40.35\%), not counting those respondents who abbreviated or omitted this information. Table 1 reports the positions each respondent reported holding. 
Table 1

Respondents' Position

\begin{tabular}{lll}
\hline Position & Frequency of responses & Percent $(\%)$ \\
\hline Head of school & 16 & 28.07 \\
Principal & 14 & 24.56 \\
Director & 11 & 19.30 \\
Coordinator & 5 & 8.77 \\
Superintendent & 5 & 8.77 \\
Counselor/Advisor & 2 & 3.51 \\
Teacher & 1 & 1.75 \\
\hline
\end{tabular}

\section{Length of Service}

Fifty-nine respondents identified the length of their service in the current role. More than half of respondents (30 or 50.85\%) indicated having served in the position between one and six years. The group average ranged between three and six years; this is compatible to Benson's (2011) findings of 3.7 years.

\section{School Characteristics}

Schools represented ranged in size from 25 to 2,200 enrolled students per respondent reports, averaging approximately $682\left(M=585, \sigma_{x}=488.71\right)$. The range of tuition fees in terms of U.S. dollars ranged from $\$ 1,500$ to $\$ 30,000$ per annum $\left(M=\$ 10,938.40, \sigma_{x}=\$ 7,711.57\right)$. One school reported that it received funding through taxation and charged no tuition of attendees. Students enrolled in international schools represented 70 different countries. Five respondents indicated that they served students from many other countries but did not provide the identities of those countries. The United States was most often represented (served by 42 of the 59 represented schools), followed distantly by Canada, China, and Korea (each represented in 25 schools).

Thirty-five schools $(59.32 \%)$ purportedly serve in an urban setting, and nearly a quarter $(23.73 \%$ or 14$)$ schools serve in a suburban setting. Only ten percent (10.17\% or six) schools serve in inner-city settings and five percent (5.08\% or three) schools serve in rural settings. One respondent indicated that the school served in a "medium town".

Most schools (53 or $91.38 \%$ of respondents) represented reported serving students with disabilities. Enrollment of students with disabilities ranged from two to $180\left(\bar{x}=37.84, M=22.5, \sigma_{x}=41.88\right)$. Based on respondent reports, $12 \%$ of the total population in international schools is comprised of students who have disabilities.

Over $86 \%$ of respondents (51) claimed an affiliation between their school and at least one of 30 international school organizations. The most frequently claimed associations included the East Asian Regional Council of Schools (11), the Council of International Schools (10), and the New England Association of Schools and Colleges (8). Seven respondents reported an affiliation with either/both of the Association of American Schools in South America and/or the European Council of International Schools. Five respondents reported an affiliation with either/both of the Michigan Department of Education and/or the International Baccalaureate. Four respondents reported an affiliation with the Association of American Schools in Mexico. Three respondents reported an affiliation with the Council of British International Schools. Two respondents reported an affiliation with either/all of the Center for International Education, Western Association of Schools and Colleges, and/or the African International Schools Association. The following organizations were each 
acknowledged as an affiliation by one respondent: Special Education Network in Asia, Japan Council of International Schools, Academy for International School Heads, Swiss Group of International Schools, SACA (researchers are not able to discern representation of acronym), Stamford American International School, Association of International Schools in Africa, Southern Association of Colleges and Schools, Association for Advancement of International Education, Association of China and Mongolia International Schools, Association of Christian Schools International, International Childcare and Education Centre, Association of American Schools of Central America, Colombia, Caribbean and Mexico, International Schools Association of Tanzania, Middle States Association of Colleges and Schools, Central and Eastern European Schools Association, Association to Advance Collegiate Schools of Business International, International Schools Association of Thailand, Agency for French Education Abroad, EdExcel Pearson, and the Chiang Mai Circle of International Schools.

Approximately $73 \%$ of schools reported no religious affiliation. Thirteen respondents reported a Christian affiliation (22.03\%). One respondent (1.69\%) claimed either Buddhist or Islamic affiliation.

\section{Correlations}

School characteristics. School enrollment demonstrated a strong, positive correlation with enrollment of students with disabilities $(r(57)=0.52, p=0.0001$, two-tailed). Researchers found no significant correlation between per annum tuition and total enrollment $(r=0.18)$ or enrollment of students with disabilities $(r=0.02)$. The correlation between the number of teachers with special education training on staff and enrollment figures of students with disabilities $(r=0.38)$ and the number of teachers on staff and total enrollment $(r=0.90)$ demonstrated a significant disparity. Table 2 compares the number of credentialed teachers purportedly serving each group type.

Table 2

Number of Credentialed Teachers Purportedly Serving Each Group Type

\begin{tabular}{lcc}
\hline & Teaching credential & Special education credential \\
\cline { 2 - 3 } & & Frequency of responses \\
\hline $0 \%$ & 0 & 4 \\
$1-9 \%$ & 0 & 8 \\
$10-19 \%$ & 1 & 6 \\
$20-29 \%$ & 0 & 5 \\
$30-39 \%$ & 0 & 2 \\
$40-49 \%$ & 1 & 2 \\
$50-59 \%$ & 1 & 3 \\
$60-69 \%$ & 2 & 0 \\
$70-79 \%$ & 2 & 0 \\
$80-89 \%$ & 9 & 1 \\
$90-99 \%$ & 17 & 6 \\
$100 \%$ & 25 & 18 \\
\hline
\end{tabular}

Table 3 demonstrates correlations between subscales and the extent of inclusion as determined by the number of enrolled students. Only combined scores on all three subscales and summative scores on the connectedness sub-portion approached significance ( $r=0.23$ and $r=0.19$, respectively).

Table 4 presents the correlations found among tests in relation to the ethics of connectedness (Frick \& Frick, 2010). Of note, significant correlations $(p=0.05)$ appeared between scores of care and 
professionalism and espousal of the CEC ethics, as well as virtue and high scores of consequentialism as indicated in responses to the vignettes. Care correlated significantly with combined scores with espousal of the CEC ethics and consequentialism $(r(60)=0.27, p=0.05$, two-tailed) as did virtue $(r(60)=0.27, p=0.05$, two-tailed). Justice indicated a strong inverse trend in relation to the CEC ethics but failed to achieve significance. The trait of professionalism demonstrate a similar tendency but also failed to achieve significance $(r(60)=0.19, p=0.05$, two-tailed). The trait of community barely missed significance $(r(60)=0.23, p=0.05$, two-tailed).

Table 3

Correlations between Subscales and the Extent of Inclusion

\begin{tabular}{ll}
\hline Variables & $r$ \\
\hline CEC Ethics \& Special Education Inclusion & +0.10 \\
Consequentialism \& Special Education Inclusion & +0.09 \\
Connectedness \& Special Education Inclusion & +0.19 \\
Combined Subscales \& Special Education Inclusion & +0.23 \\
\hline
\end{tabular}

Table 4

Correlations Found Among Tests in Relation to the Ethics of Connectedness (Frick \& Frick, 2010)

\begin{tabular}{llll}
\hline & CEC Ethics & Consequentialism & CEC \& Consequentialism \\
\hline Care & $+0.28^{*}$ & +0.02 & $+0.27^{*}$ \\
Community & +0.11 & +0.13 & +0.23 \\
Critique & +0.01 & +0.09 & +0.10 \\
Justice & -0.17 & +0.05 & -0.11 \\
Professionalism & $+0.28^{*}$ & -0.07 & +0.19 \\
Virtue & +0.02 & $+0.25^{*}$ & $+0.27^{*}$ \\
\hline
\end{tabular}

Note. ${ }^{*} r(60)=x, p=0.05$, two-tailed.

Inclusion, connectedness, and CEC ideologues. Figure 2 demonstrates the relationship between aggregate scores of the espousal of CEC ethics and the aggregate scores of consequentialism. Researchers found a significant, inverse correlation between scores on espousals of the CEC ethics and high scores on consequentialism $(r(59)=-0.44, p=0.001$, two-tailed) but no significant relationship between either CEC ethics espousal and connectedness $(r=0.215)$ or connectedness and consequentialism $(r=0.174)$. Removing items that demonstrated weak statistical reliability during piloting had insignificant impact on the resulting correlations.

The significance of the correlation between CEC ethics espousal and consequentialism lapsed when responses to non-antagonistic scenarios were omitted. However, omitting responses to antagonistic scenarios produced no significant change.

Table 5 provides summative item analysis of Likert scale items used in the consequentialism subscale. Responses to scenarios one and three each demonstrated wide variance in at least one item. Responses to scenarios two and four demonstrated overall moderate variance.

Table 6 demonstrates descriptive statistics for response patterns pertaining to each of the four scenarios used in the consequentialist-non-consequentialist sub-section of the survey, where higher mean scores indicate a tendency toward consequentialism. Patterns in responses suggest no overall allegiance to either a consequentialist or non-consequentialist perspective $(\alpha=0.53)$. However, a variation in subscription to one or 
the other perspective appears when considering the nature of the infraction-specifically in regards to whether the nature of the infraction involved antagonism or merely inconvenience. A $t$-test analysis for paired samples for means indicated a statistically significant difference, for example, between response patterns between the first and second scenarios $(t$-test, two-tailed $p$-level $=0.0001)$.

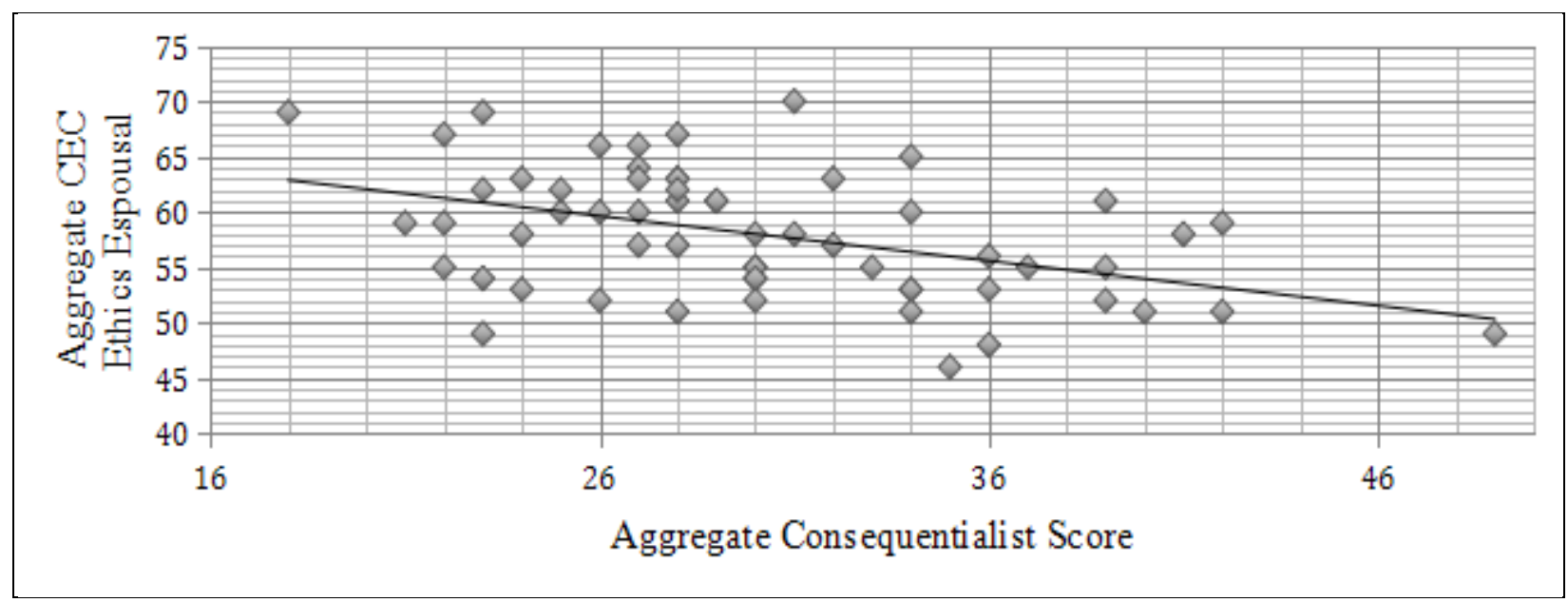

Figure 2. Relationship between aggregate scores of the espousal of CEC ethics and the aggregate scores of consequentialism.

Table 5

Correlations Found Among Tests in Relation to the Ethics of Connectedness (Frick \& Frick, 2010)

\begin{tabular}{llll}
\hline & CEC Ethics & Consequentialism & CEC \& Consequentialism \\
\hline Care & $+0.28^{*}$ & +0.02 & $+0.27^{*}$ \\
Community & +0.11 & +0.13 & +0.23 \\
Critique & +0.01 & +0.09 & +0.10 \\
Justice & -0.17 & +0.05 & -0.11 \\
Professionalism & $+0.28^{*}$ & -0.07 & +0.19 \\
Virtue & +0.02 & $+0.25^{*}$ & $+0.27^{*}$ \\
\hline
\end{tabular}

Note. ${ }^{*} r(60)=x, p=0.05$, two-tailed.

Table 6

Descriptive Statistics for Response Patterns

\begin{tabular}{|l|l|l|l|l|l|}
\hline & Theme & Mean & Median & Variance & Standard Deviation \\
\hline Scenario 1 & $\begin{array}{l}\text { Parents complain about special } \\
\text { accommodations interfering with } \\
\text { "abled" children's learning }\end{array}$ & 1.83 & 1.00 & 1.5 & 1.23 \\
\hline Scenario 2 & $\begin{array}{l}\text { Student's father threatens corporal } \\
\text { punishment for involvement in altercation }\end{array}$ & 3.45 & 2.00 & 2.81 & 1.68 \\
\hline Scenario 3 & $\begin{array}{l}\text { Unauthorized search results in discovery } \\
\text { of weapon }\end{array}$ & 2.46 & 2.00 & 2.10 & 1.45 \\
\hline Scenario 4 & $\begin{array}{l}\text { Academically struggling student requests } \\
\text { employment reference }\end{array}$ & 2.30 & 2.00 & 1.43 & 1.20 \\
\hline
\end{tabular}

\section{Discussion}

\section{Limitations}

The limitations of this study are situated in the variables associated with each international school (Sperandio \& Klerks, 2007, p. 140). Countries vary as to what qualifies a child as having a disability. 
Categories of disability that exist in one country, e.g., learning disabilities and attention deficit/hyperactive disorder, may not be considered an area of disability in another country (Ferrari, 2014; Sperandio \& Klerks, 2007). Furthermore, the types of disabilities served within an international school are not known. Cultural backgrounds of the school administrator also impact survey responses. The Ethics of Connectedness (Frick \& Frick, 2010) and the CEC Ethics (2010) represent United States administrators and best practices, and the alignment of these ethics to individual country's cultural norms is unknown. In addition, no formal definition of inclusion exists. How inclusion is implemented varies not only from country to country, but from school to school. Finding a common definition of and experience in inclusive environments is challenging, if not impossible. Special education professional training and the expectations of international school training for special education teachers also varies.

\section{Conclusions}

This study was a quantitative correlational study regarding the Ethics of Connectedness (Frick \& Frick, 2010), the CEC Ethical Principles and Practice Standards (2010), and consequentialism as it relates to administrators' dispositions towards inclusive practices. Participants overwhelmingly represented the United States philosophy which necessitates further research to understand the influence of culture on the outcomes reported herein. The correlation between total enrollment and enrollment of children with disabilities indicates that the larger enrollment size of the school as is the larger number of children with disabilities served. Conversely, responses also reflected a disproportionate number of appropriately credentialed teachers serving as a function of the setting type. It is unclear, however, how school administrators determined whether or not teachers were properly trained. Variables may include expectations of the host country, school administrators' previous experiences in working with special education professionals, or the perception that children with disabilities are not being properly supported within the school. Lastly, it may be concluded from the data that tuition does not appear to impact total enrollment, enrollment of children with disabilities, nor enrollment of typical peers.

The study also sought to determine, what, if any, correlation existed between the Ethics of Connectedness (Frick \& Frick, 2010), CEC (2010), and consequentialism, and inclusive practices. Aggregate data did reflect an inverse correlation between CEC ethics and consequentialism. Services for children with disabilities are designed to address the needs of each individual student as reflected in the United States Individuals with Disabilities Education Act (2004) and do what is in the best moral value of the child. Therefore, one may seek to conclude that there is a direct correlation between the CEC ethics and consequentialist theory. The data also reflects that consequential subscale scenarios which were antagonistic v. merely inconveniences in nature may reflect international school administrators' willingness to be more open to conversations that support a child with disabilities.

Correlations between Connectedness (Frick \& Frick, 2010), CEC Ethics (2010) and consequentialism subscales were noted in the data. Correlations were present in the Connectedness of care and professionalism and the espousal of CEC ethics. As indicated by Frick and Frick (2010), care is the ability to act in a manner which is for the well-being of others, and in particular, those who are different than one's self and profession as a means of placing students' interest in the center of conversation. Therefore, it may be concluded that international school administrators demonstrate that when serving children with disabilities, there is an effort to meet the individual needs of the child. A correlation was also drawn between the Connectedness of virtue and 
consequentialism. Frick and Frick (2010) define virtue as the ability to dialogue openly while being sensitive. The correlation of care and virtue with the CEC Ethics and consequentialism may reflect an international school administrator's willingness to converse with others regarding a child with disabilities prior to making decisions which will impact the child and/or the entire student body.

\section{Recommendations}

The current study did reflect a lack of teacher training for those serving children with disabilities. Insight as to training expectations as related to host country special education practices, types of disabilities served within a given international school, and school administrator expectations of special education professionals may provide further insights.

In an effort to support special education services in international schools, further research is needed to understand the cultural perspective that international school administrators bring with them to the host country in which they will serve. Further disaggregation of the data from this study may allow the researchers to determine, in particularly, if international school administrators from the United States correlate with Connectedness (Frick \& Frick, 2010) and the CEC ethics (2010) more so than those who indicated other nationalities.

Consequently, if a conclusion can be drawn that international school administrators first served as an educator or administrator in their home country, a study regarding Connectedness (Frick \& Frick, 2010) and the CEC ethics (2010) with school administrator participants who currently serve in the United States may shed further insight as to the special education perceptions that United States international school administrators hold.

\section{References}

Anderson, D. W. (2011). Hospitable classrooms: Biblical hospitality and inclusive education. Journal of Education and Christian Belief, 15(1), 13-27.

Anderson, D. W. (2006). Inclusion and idterdependence: Students with special needs in the regular classroom. Journal of Education and Christian Belief, 10(1), 43-59.

Bakken, J. P., \& Smith, B. A. (2011). A blueprint for developing culturally proficient/responsive school administrators in special education. Learning Disabilities: A Contemporary Journal, 9(1), 33-46.

Barnes, J. (Ed). (2015). John Catt's guide to international schools 2015/16 (13th ed.). Suffolk, UK: John Catt Educational Ltd..

Bartlett, K. (2014). Included, challenged, successful. UMC United World, 18-19. Retrieved from http://www.thecgcproject.org/uploaded/UWC_United_World_April_2014_10.pd?1400813502863

Benson, J. (2011). An investigation of chief administrator turnover in international schools. Journal of Research in International Education, 1(10), 87-103. doi: http://dx.doi.org/10.1177/1475240911398779

Brown, C. (2011). Consequentialize this*. Ethics, 121(4), 749-771. doi: 00141704/2011/121040003

Bunnell, T. (2006). Managing the role stress of public relations practitioners in international schools. Educational Management Administration \& Leadership, 34(3), 385-409. doi: 10.177/1741143206065271

Conderman, G., \& Pedersen, T. (2005). Promoting positive special education practices. NASSP Bulletin, 89(644), 90-98.

Council for Exceptional Children. (2010). Special education professional ethical principles and practice standards. Retrieved from http://www.cec.sped.org/Standards/Ethical-PrinciplesandPractice-Standards?sc_lang=en

Darwall, S. L. (2005). Theories of ethics. In R. G. Frey, \& C. H. Wellman (Eds.), A companion to applied ethics (pp. 17-37). Malden, M.A.: Blackwell Publishing.

DiPaola, M., Tschannen-Moran, M., \& Walther-Thomas, C. (2004). School principals and special education: Creating the context for academic success. Focus on Exceptional Children, 37(1), 1-10.

Driver, J. (2012). Consequentialism. New York, N.Y.: Routledge.

Ferrari, L. (April, 2014). What can we learn from Italy's 36 years of wide-range inclusion. Paper session presented at the Meeting of the Council for Exceptional Children, Philadelphia, P.A.. 
Fiedler, C. R., \& Van Haren, B. (2009). A comparison of special education administrators' and teachers' knowledge and application of ethics and professional standards. The Journal of Special Education, 43(3), 160-173. doi: 10.1177160322466908319305

Frick, W. C., Faircloth, S. C., \& Little, K. S. (2013). Responding of the collective and individual "best interest of students": Revisiting the tension between administrative practice and ethical imperatives in special education leadership. Educational Administration Quarterly, 49(2), 207-242. doi:0771003\&X2463230

Frick, J. E., \& Frick, W. C. (2010). An ethic of connectedness: Enacting moral school leadership though people and programs. Education, Citizenship, and Social Justice, 5(117), 8-30. doi: 10.1171/1746197910370729

Global Partnership for Education. (2015). Children with disabilities. Retrieved from http://www.globalpartnership.org/focusareas/children-with-disabilities

Hansen, B. A., \& Morrow, L. E. (2012). Invitational inclusive education: First steps on a journey to develop perspectives and practices. Journal of Invitational Theory and Practice, 18, 37-44.

Helton, G., \& Ray, B. (2009). Administrative pressures to practice unethically: Research and suggested strategies. Ethical Human Psychology and Psychiatry, 11(2), 112-119.

Hooker, B. (2010). Consequentialism. In J. Skorupski (Ed.), The Routledge companion to ethics (pp. 444-466). New York, N.Y.: Routledge.

Jabal, E. (2013). Institutional identiy and school-community matters: "Encapsulated" and "inclusive" lessons for engagement from two international schools in Hong Kong. Journal of Research in International Education, 12(2), 3-21. doi: 10.1.1177/1475240913278066

Kune, N. (1992). The need to belong: Rediscovering Maslow's hierarchy of needs. In R. A. Villa, J. S. Thousand, W. Stainback, \& S. Stainback (Eds.), Restructuring for caring \& effective education: An administrative guide to creating heterogeneous schools (pp. 25-38). Baltimore, M.A.: Paul H. Brookes Publishing Co. Inc..

Kusuma-Powell, O., \& Powell, W. (2004). Count me in! (4th ed.). Washington, D.C.: Overseas Schools Advisory Council. Retrieved from http://www.state.gov/m/a/os//44044.htm

Mill, J. S. (2003). From unitarianism. In S. Darwell (Ed.), Consequentialism (pp. 32-66). Malden, M.A.: Blackwell Publishing.

Next Frontier Inclusion. (2015). Our mission. Retrieved from http://www.nextfrontierinclusion.org/our-mission/

Office of Overseas Schools. (2014/2015). Overseas schools offering support to children with special needs 2014-2015. Retrieved from http://www.state.gov/documents/organization/176076.pdf

Office of Special Education. (2004). Individuals with disabilities education act ([34 300.137] [20 U.S.C. 1412(a)(10)(A)]). Washington, D.C.: U.S. Government Printing Office.

Scanlon, T. M. (1998). Introduction. In S. Scheffler (Ed.), Consequentialism and its critics (pp. 74-92). New York, N.Y.: Oxford Press.

Scheffler, S. (1998). Introduction. In S. Scheffler (Ed.), Consequentialism and its critics (pp. 1-13). New York, N.Y.: Oxford Press.

Sergiovanni, T. J. (2007). Rethinking leadership: A collection of articles (2nd ed.). Thousand Oaks, C.A.: Sage Publishing Company.

Shaklee, B. D. (2007). Focus on international schools: Serving students with learning disabilities. In T. E. Scruggs, \& M. A. Mastropieri (Eds.), International perspectives (pp. 265-283). Oxford, UK: Elsevier Ltd..

Shelden, D. L., Angell, M. E., Stoner, J. B., \& Roseland, B. D. (2010). School principals' influence on trust: Perspectives of mothers of children with disabilities. The Journal of Educational Research, 103(3), 159-170. doi: : 10.1080/00220670903382921

Smith, R., \& Leonard, P. (2005). Collaboration for inclusion: Practitioners perspectives. Equity \& Excellence in Education, 38 , 269-279.

Sperandio, J., \& Klerks, J. (2007). Leadership challenge: Blending inclusive special needs provision and reform of teaching methodology in a Dutch international school. International Journal of Special Education, 22(2), 140-149.

Strike, K. A., \& Soltis, J. F. (2009). The ethics of teaching. New York, N. Y.: Teachers College, Columbia University.

Tasioulas, J. (2010). Justice and punishment. In J. Skorupski (Ed.), The Routledge companion to ethics (pp. 680-691). New York, N.Y.: Routledge.

United Nations. (2013). International migration report 2013. Retrieved from http://www.un.org/en/development/desa/population/publications/migration/migration-report-2013.shtml 
United Nations Educational, Scientific, and Cultural Organization (2015). Learning to live together. Retrieved from http://en.unesco.org/themes/learning-live-together

United Nations General Assembly. (2006, Dec. 6). Convention on the Rights of Persons with Disabilities. Retrieved from http:// www.un.org/disabilities/default.asp?id=259

Wendel, F. C., Hoke, F. A., \& Joekel, R. G. (1996). Outstanding school administrators: Their keys to success. Westport, C.T.: Praeger.

William, J. L., Pazey, B., Shelby, L., \& Yates, J. R. (2013). The enemy among us: Do school administrators perceive students with disabilities as a threat? NASSP Bulletin, 97(2), 39-65. 